\title{
Publication Patterns of U.S. Academic Librarians and Libraries from 2003 to 2012
}

\author{
Deborah D. Blecic, Stephen E. Wiberley Jr., Sandra \\ L. De Groote, John Cullars, Mary Shultz, and Vivian \\ Chan
}

This study investigated contributions to the peer-reviewed library and information science (LIS) journal literature by U.S. academic librarian (USAL) authors over a ten-year period (2003-2012). The results were compared to those of two previous five-year studies that covered the time periods of 1993-1997 and 1998-2002 to examine longitudinal trends. For USAL authors as a group, publication productivity, the proportion of peerreviewed articles contributed to the LIS literature, and sole-authorship declined. Among USALs who did publish, productivity patterns remained similar over twenty years, with a slight increase in the percentage of USAL authors who published three or more articles in five years. The top twenty high-publication libraries from 2003 to 2012 were from public research universities, unlike two earlier studies that found private university libraries among the top twenty.

\section{Introduction}

Library and information science (LIS) is a field where practitioners make substantial contributions to the literature and bring a unique perspective. ${ }^{1}$ Two previous studies conducted by Wiberley, Hurd, and Weller (WHW) documented U.S. academic librarian (USAL) productivity in a large sample of LIS journals over two five-year periods, 1993-1997 and 1998-2002. ${ }^{2}$ The studies found slight declines from the first time period to the second in both the total number and percentage of refereed articles by USAL authors, the percentage of authors that were USALs, and coauthorship rates of USALs.

The present study repeated the WHW studies, with some additional analysis, for the time period 2003-2012 to see if the changes observed were indicative of long-term trends or just momentary variations. The two WHW studies are heavily referenced

\footnotetext{
* Deborah D. Blecic is Collections Coordinator and Professor, Stephen E. Wiberley Jr. is Bibliographer for the Social Sciences and Professor, Sandra L. De Groote is Scholarly Communication Librarian and Professor, and John Cullars is Associate Professor Emeritus, all at the University of Illinois at Chicago Library; e-mails:dblecic@uic.edu,wiberley@uic.edu, sgroote@uic.edu,and jcullars@uic.edu.Mary Shultz is Director and Associate Professor in the Savitt Medical Library at the University of Nevada, Reno School of Medicine; e-mail: mshultz@med.unr.edu.Vivian Chan is a student; e-mail:VivianChanVC@gmail.com. (C2017 Deborah D. Blecic, Stephen E. Wiberley Jr., Sandra L. De Groote, John Cullars, Mary Shultz, and Vivian Chan, Attribution-NonCommercial (http://creativecommons.org/licenses/by-nc/4.0/) CC BY-NC.
} 
for comparison in the discussion section of this paper, but not discussed in the review of literature. The acronym WHW refers to both previous studies. The present study explored the same research questions as the previous WHW studies. In addition, it examined trends over the twenty-year period 1993-2012 and examined some characteristics of top-producing libraries that the WHW studies had not explored. Research questions included:

- Do U.S. academic librarians continue to contribute a significant portion of articles to the peer-reviewed LIS journal literature?

- What is the frequency of coauthorship for U.S. academic librarians, and has there been a change over twenty years?

- What are the productivity benchmarks for U.S. academic librarians, and how have they changed over twenty years?

- Which U.S. academic libraries produce the most publications, and what are the characteristics of those libraries, including tenure status and staffing?

\section{Review of Literature}

In the years since the WHW studies, there have been a number of publications that have addressed the main areas of interest of the present study: productivity of academic librarians, contributions of different libraries, and extent of coauthorship. Articles have also investigated the relationship between faculty status and productivity and whether the contributions to the literature by practitioners have declined.

Coauthorship rates have been studied in various samples of the literature. Soutter analyzed a population of seventy-four peer-reviewed articles about academic librarian competency, published between 2001 and 2005. She found that 46.5 percent had multiple authors. ${ }^{3}$ In a sample of 500 articles taken from four journals published between 2001 and 2007, Norelli and Harper found that 52 percent had two or more authors. ${ }^{4}$ Kenefick and Werner studied characteristics of refereed articles in one journal, Medical Reference Services Quarterly (MRSQ) for 29 years, 1982-2009. They noted an increase in coauthorship over time from 38 percent in the 1980s to 50 percent in the 1990s to 59 percent in the 2000s. ${ }^{5}$ In a study of articles published by Tennessee academic librarians between 2007 and 2011, Wood and Park found that 53 percent had two or more authors. ${ }^{6}$ In summary, coauthorship rates have been between 46 percent and 59 percent since 2000 in the LIS journal literature, and there is evidence that the rate of coauthorship has increased over time.

Regarding the types of institutions that produce publications, Kenefick and Werner's analysis of MSRQ's refereed articles found that 69 percent of the 791 articles were produced by authors from academic health sciences libraries. ${ }^{7}$ Wood and Park found that 35 percent of Tennessee academic librarian authors were from research universities with a Carnegie Classification of very high or high research activity, and another 20 percent were from doctoral research universities. ${ }^{8}$ Stewart analyzed the affiliations of U.S. librarian authors of articles in "the top ten library science journals [as] ranked by 5-year impact factor as derived from Thompson Reuters ISI Web of Knowledge Journal Citation Reports" in the year 2009. He found that 80 percent of the librarian authors were from public university libraries, even though "public institutions comprise roughly $40 \%$ of postsecondary institutions in the United States." Also, although Association of Research Libraries (ARL) members were only a fraction of U.S. academic libraries, they were the homes of more than half of the authors. Finally, librarians from the Carnegie Classification RU/VH-Research University (very high research activity) supplied more than 50 percent of the authors, even though they constituted only 2 percent of institutions of postsecondary education in the United States. ${ }^{9}$

Galbraith, Smart, Smith, and Reed studied the status and background of U.S. authors of peer-reviewed articles in 23 high-impact LIS journals published in the United 
States in 2007 and 2009. They found that, among academic librarian authors, 64 percent had both faculty status and were in a tenure system, 19 percent were without faculty status but within a tenure system, 12 percent had faculty status only, and 5 percent did not have faculty status and were not in a tenure system. ${ }^{10}$ Seaman studied the author affiliations of North American authors for five high-impact LIS journals. He found that, among the top ten institutions, four offered tenure to librarians and three offered a variation of continuing appointments. He also found that, for thirty-six of the top producing institutions, the correlations between productivity and each of three variables were weak: ARL membership, presence of a PhD-granting library school, and number of professional staff. ${ }^{11}$

Regarding trends in the contributions of librarians to the LIS literature, Finlay, Ni, Tsou, and Sugimoto studied weighted samples of articles in twenty LIS journals for two periods: 2002-2006 and 2007-2011. They found that the percentage of articles authored by librarians decreased by 7 percent and the total number of articles with librarian authors declined by 8 percent, while the total number of articles published within those journals increased by 13 percent. ${ }^{12}$ Wirth, Kelly, and Webster documented a generally upward trend in publication of peer-reviewed articles between 1998 and 2007 among librarians at Oregon State University. ${ }^{13}$ Best and Kneip conducted a wide-ranging study of faculty status, tenure requirements, publication, and library school education of academic librarians who published articles in College and Research Libraries (CERL) and Journal of Academic Librarianship (JAL) between 1993 and 2002. Their data showed a decline of 8 percent in librarian-authored articles from 1993-1997 to 1998-2002, from 70 percent to 62 percent. ${ }^{14}$ Walters and Wilder's study of articles published between 2007 and 2012 in thirty-one LIS journals found that librarians contributed only 23 percent, the lowest percentage reported among studies reviewed. ${ }^{15}$

Despite the decline in publication by academic librarians in CERL and JAL reported by Best and Kneip, their survey of ARL library directors suggested "an increase in publication expectations for promotion" in both faculty status and professional status libraries. ${ }^{16}$ Sassen and Wahl's 2011 follow-up survey to that of the 1987 study by Cosgriff, Kenney, and McMillan found an increase in the number of ARL libraries requiring publication for promotion. ${ }^{17}$ If overall publication productivity of U.S. academic librarians is declining, as some available research suggests, it is despite greater expectations for research productivity than in the past.

In summary, recent studies point to an increase in coauthorship and a decrease in librarians' contributions to the LIS literature. Despite these findings, an increase in publication expectations was reported for ARL libraries. Libraries with faculty status and/or tenure expectations and those that served doctoral universities were high contributors to the LIS literature. The present study examined U.S. academic librarians' and libraries' contributions to a subset of the LIS literature over a ten-year period, with comparison to two earlier five-year periods to determine trends over twenty years. The present study also explored characteristics of the top-producing libraries, including staffing levels over twenty years.

\section{Methodology}

Of the studies discussed in the review of literature, each examined publishing activity in a sample of journals. A fundamental issue for the present study was determining the list of journals to analyze. In the first WHW study (1999), the authors identified thirty-two LIS journals for inclusion. The second article by WHW (2006) analyzed publication patterns in the same set of journals plus two additional titles: Medical Reference Services Quarterly and Journal of Interlibrary Loan, Document Delivery E Electronic Reserve (formerly Journal of Interlibrary Loan, Document Delivery E Information Supply). Because 
the authors of the present study wished to compare their results with the findings of WHW, they too included the same thirty-four journals. ${ }^{18}$ The authors also reviewed the current landscape of LIS journal publishing and included seven new journal titles that had indicators of importance to the field and were publication outlets for U.S. academic librarians. The seven other new titles in this study were Collection Building, College \& Undergraduate Libraries, Internet Reference Services Quarterly, New Library World, portal: Libraries and the Academy, Reference Librarian, and Serials Review. The seven new journals each met the following criteria:

1. Ulrichsweb Global Serials Directory assigned: a) a subject heading of library and information science; b) a status of refereed; c) a language of English; and d) a start year of 2002 or earlier. The authors verified the refereed status of journals so listed by examining issues of each.

2. Journals that met criterion 1 also had to either a) be covered by Journal Citation Reports or b) have a Q1 or Q2 SCImago ranking.

3. Journals that met criterion 1 and 2 also had to have published forty or more articles between 2005 and 2011 by authors who had a U.S. library affiliation. To apply this criterion, the authors searched Web of Science and Scopus between the years 2005 and 2011 for the number of articles that included variations of the words library and USA in the affiliation or address field. Document types were limited to article or review.

The present study, like the previous WHW studies, did not cover all possible LIS journals where U.S. academic librarians publish. But it did capture a subset of important journals for USAL authors and examine the patterns within these journals. The complete list of journals studied is found in the results section.

For each journal issue published between 2003 and 2012, the authors recorded the following information: total number of refereed articles, number of refereed articles with at least one USAL author, total number of authors for each refereed article, the number of authors who were U.S. academic librarians, the name of each USAL, their affiliation, and their non-USAL coauthors' names and titles. Editorials, introductions, columns, letters to the editor, perspective/opinion pieces, book/electronic resource reviews, news items, committee reports, obituaries, interviews, and annual bibliographies were not counted as refereed articles. Articles that were part of conference proceedings or special theme issues were only included if there was evidence of peer review for the article or entire issue. For journals that provided the information, an interval of twenty-five or more days between submission and acceptance was considered evidence of peer review. Many journals had different types of refereed articles; for example, refereed articles in the Journal of the Medical Library Association included those published as "papers," "brief communications," "research reports," "case studies," and sometimes "symposia."

Librarians from U.S. academic institutions ranging from doctoral universities to community colleges were counted as USALs. If there was a question about an institution, it was included if listed by the Carnegie Classification of Institutions for Higher Education. ${ }^{19}$ Librarians from other countries were not counted in this study. If there was a question about whether or not an author was a librarian, the study team searched the Internet for evidence that the person had earned an MLS or equivalent. If an author affiliated with an academic institution held an MLS degree but did not work for the library but for some other campus unit, he or she was not considered a USAL. Emeritus librarians were included in the study, as they are faculty at their library. Also, research projects can often span multiple years from data gathering and analysis to publication, and it is possible that a librarian can retire in the time it takes for research to move from data gathering and analysis to publication. Thus an article may have been completed while an author was a working faculty member but published after the author retired. 
The study team then standardized both institution and individual names before analyzing the data. Articles reported each author's institutional affiliation, and the study team initially entered the affiliation as reported into the data set. For all U.S. academic librarians, the study team then standardized the affiliation by comparing the reported affiliation with the official name of the institution as given by its regional accreditation agency. These agencies are: New England Association of Schools and Colleges, Middle States Commission on Higher Education, Southern Association of Colleges and Schools Commission on Colleges, Higher Learning Commission of the North Central Association, WASC Senior College and University Commission of the Western Association of Schools and Colleges, and the Northwest Commission on Colleges and Universities of the Northwest Association of Schools and Colleges. Accreditation agency listings also showed whether geographically dispersed institutions were accredited separately or as one. For example, Pennsylvania State University listed twenty-five geographically separate campuses on its website at the time of this study but all were accredited together. ${ }^{20}$ Consequently, when counting publications by librarians at Penn State, the study team totaled those articles by librarians at the Abington, York, and other locations with articles by librarians at University Park, the largest campus. For multisite institutions with separately accredited campuses, the study team counted each campus separately, such as the University of Illinois at Chicago, at Urbana-Champaign, or at Springfield. Further, when an article reported an author affiliation of a multisite university with only the stem name, for example, University of California, the study team searched the Internet to determine the author's particular campus (for example, Berkeley) at the time of the article's publication.

Standardizing author names was more difficult than standardizing institutional names. The study team ran a pivot table of authors' names sorted alphabetically by first name, and then reviewed the list of 4,329 name variants. When similar variants were found, the study team checked the data set and often conducted an Internet search to determine if the name variants referred to the same person. For example, if the study team found that Jane C. Smith and Jane Cooper Smith referred to the same person, then they standardized the name. Sandra Thompson was compared with Sandy Thompson, Carol M. Jones with Carol M. Jones Philips, Anthony Johnson with Tony Johnson, and so on. After checking the data by name sorting, the data set was then sorted by institution and scanned again to see if name variants were spotted within an institution, such as Adam Jones and John Adam Jones. Some name variants were possibly missed, especially in cases of a complete last name change. But the study team attempted to standardize as many names as possible. The trend of posting CVs with publication lists on the Internet helped immensely with standardizing an individual's name variants. Ultimately, standardization reduced the list of unique names from 4,329 to 3,870.

To address the question of what are the characteristics of the U.S. academic libraries that produced the most publications, the study team examined three aspects of the twenty libraries that produced the highest number of peer-reviewed articles over the ten-year study period: academic status, number of professional staff, and Carnegie Classification. The number of professional staff was determined by consulting the ARL or Association of College and Research Libraries (ACRL) statistics; so, by virtue of the source of the statistics, the number of libraries that were ARL libraries was also discovered.

Promotion and tenure status for the top twenty libraries was examined at the website "Academic-Librarian-Status" as of 2015. ${ }^{21}$ If the status was unclear, the website of the individual library was examined for clarification. The study team gathered the number of professional staff for each year in the time period 1993 to 2012, if available. ARL Libraries regularly reported the number of professional staff, so the data were easy 
to gather for ARL libraries. ${ }^{22}$ Seventeen of the top twenty libraries were ARL libraries with data for each year. For non-ARL libraries, the ACRL statistics also reported the number of professional staff, but yearly reporting by individual libraries was less consistent. ${ }^{23}$ Mississippi State, Oregon State, and University of Nevada, Las Vegas reported their data in the ACRL statistics, and each was missing some years. Both sets of statistics reported the number of professional staff (which included librarians) by FTE. The study team calculated averages for the years in which data were reported.

Two limitations of the present study were already mentioned: only a subset of LIS journals was examined and librarians with emeritus status were included. While the subset attempted to capture the major LIS journals in which USAL authors were publishing, the data were not a complete picture of USAL publishing, but a sample. By including librarians with emeritus status, the study team credited both librarians and libraries with articles completed while the individual was a working librarian but not published until after retirement; however, the team may also have counted some articles written after retirement. Another limitation was that evidence of peer-review varied greatly from journal to journal, and judgment calls were sometimes necessary, in addition to consulting the Ulrich's designation.

The study team discussed all questions to try to ensure consistency. Further, the study team regularly discussed application of all criteria for inclusion and spot-checked each other's work. Nevertheless, as a group effort, there were bound to be some differences in coding.

\section{Results and Discussion}

The authors examined 1,698 issues published by 41 LIS journals between 2003 and 2012 and found a total of 10,575 refereed articles, of which one or more USALs authored 3,913 (37\%). Two of the journals ceased publication in the first half of the study, in 2004 and 2007. Overall, 3,870 USALs from 696 different libraries contributed at least one peer-reviewed article to journals studied. Table 1 summarizes, for the entire ten-year period 2003-2012 and for the subperiods 2003-2007 and 2008-2012, the contributions of USAL authors to the LIS literature in the journals studied, including instances of authorship. In table 1, an "instance of authorship" is defined as each time a person was an author or coauthor of an article. For example, if there was an article with two authors and another article with three authors, those two articles have five instances of authorship.

The two WHW studies chose prominent LIS journals in which U.S. academic librarians were publishing. This study included more journals than the WHW studies and dropped some WHW titles as they ceased publication or merged, but overall the journal lists of the three studies are comparable in scope. WHW found that, in the five-year period 1993-1997, among all the articles in the journals they studied, the number of articles with at least one academic librarian author was 43.57 percent. This proportion declined to 39.56 percent in their next study (1998-2002). The present study found that the percentage of articles with at least one USAL author was 39.64 percent in the 2003-2007 time period and dropped to 34.60 percent in the 2008-2012 period. A similar decline was found for the percentage of author instances by USALs. The percentages declined in each five-year period: 37.10 percent, 34.33 percent, 33.29 percent, and then 27.84 percent by the 2008-2012 period. Over twenty years, there is evidence of a decline in the percentage of the LIS literature contributed by U.S. academic librarians.

Direct comparison of counts of articles, rather than percentages, with the WHW studies is complicated by the different journal lists. However, despite two journals ceasing during this study, it is noteworthy that, in a comparison between the two time periods 2003-2007 and 2008-2012, the overall number of peer-reviewed articles 


\section{TABLE 1}

\section{Summary of Contributions of U.S. Academic Librarians to the Journals Studied}

\begin{tabular}{|l|c|c|c|}
\hline & $\begin{array}{c}\mathbf{2 0 0 3 - 2 0 1 2} \\
\text { (Ten Years) }\end{array}$ & $\begin{array}{c}\mathbf{2 0 0 3 - 2 0 0 7} \\
\text { (Five Years) }\end{array}$ & $\begin{array}{c}\mathbf{2 0 0 8 - 2 0 1 2} \\
\text { (Five Years) }\end{array}$ \\
\hline Journals studied & 41 & 41 & 39 \\
\hline Issues in journals studied & 1,698 & 855 & 843 \\
\hline Number of refereed articles & 10,575 & 5,038 & 5,537 \\
\hline $\begin{array}{l}\text { Number of refereed articles with at least one } \\
\text { USAL author }\end{array}$ & 3,913 & 1,997 & 1,916 \\
\hline $\begin{array}{l}\text { Percentage of refereed articles with at least } \\
\text { one USAL author }\end{array}$ & $37.00 \%$ & $39.64 \%$ & $34.60 \%$ \\
\hline Instances of authorship & 20,823 & 9,372 & 11,451 \\
\hline Instances of USAL authorship & 6,308 & 3,120 & 3,188 \\
\hline $\begin{array}{l}\text { Percentage of instances of authorship by } \\
\text { USALs }\end{array}$ & $30.29 \%$ & $33.29 \%$ & $27.84 \%$ \\
\hline $\begin{array}{l}\text { Average number of USAL authors per USAL } \\
\text { article }\end{array}$ & 1.61 & 1.56 & 1.66 \\
\hline Number of sole-authored USAL articles & 1,916 & 1,026 & 890 \\
\hline Number of coauthored USAL articles & 1,997 & 971 & 1,026 \\
\hline $\begin{array}{l}\text { Percentage of USAL articles that were } \\
\text { coauthored }\end{array}$ & $51.04 \%$ & $48.62 \%$ & $53.55 \%$ \\
\hline Number of unique USAL author names & 3,870 & 2,182 & 2,268 \\
\hline Number of unique institutions & 696 & 515 & 511 \\
\hline & & & \\
\hline
\end{tabular}

increased from 5,038 to 5,537 in the journals studied, but the number of articles with at least one USAL author decreased from 1,997 to 1,916. This is further evidence of a decline in contributions by USAL authors to the LIS literature and is similar to the findings of Finlay et al., which noted a decrease in librarian contributions coupled with growth in the literature overall in recent years. ${ }^{24}$

In studying the frequency of sole and coauthorship, WHW found that the number of USAL articles that were coauthored had decreased from 44.97 percent to 40.09 percent over their two studies. For the two five-year periods studied here, the percentage of coauthored articles went from 48.62 percent to 53.55 percent. So the trend found by WHW reversed itself for this set of journals over the ten years of this study: sole authorship decreased and coauthorship increased. This finding is similar to the findings of Kenefick and Werner, who found an increase in coauthorship rates over twentyeight years in the journal MRSQ. ${ }^{25}$ Corresponding to this trend, the average number of authors per article increased from 1.56 in 2003-2007 to 1.66 in 2008-2012, and the number of instances of USAL authorship increased from 3,120 to 3,188 despite a decline in the number of articles with at least on USAL author. Figure 1 shows twenty-year trends for three variables.

These findings raise interesting questions about the relationship between coauthorship and the overall productivity for a profession. Does increasing coauthorship result in a decrease in the overall number of publications? The data for the ten years of this study suggest this correlation, but the WHW data do not show the same trends. Many factors could be interacting to influence these trends. Coauthorship may allow for tackling bigger or more complex projects that require more authors to be involved, 


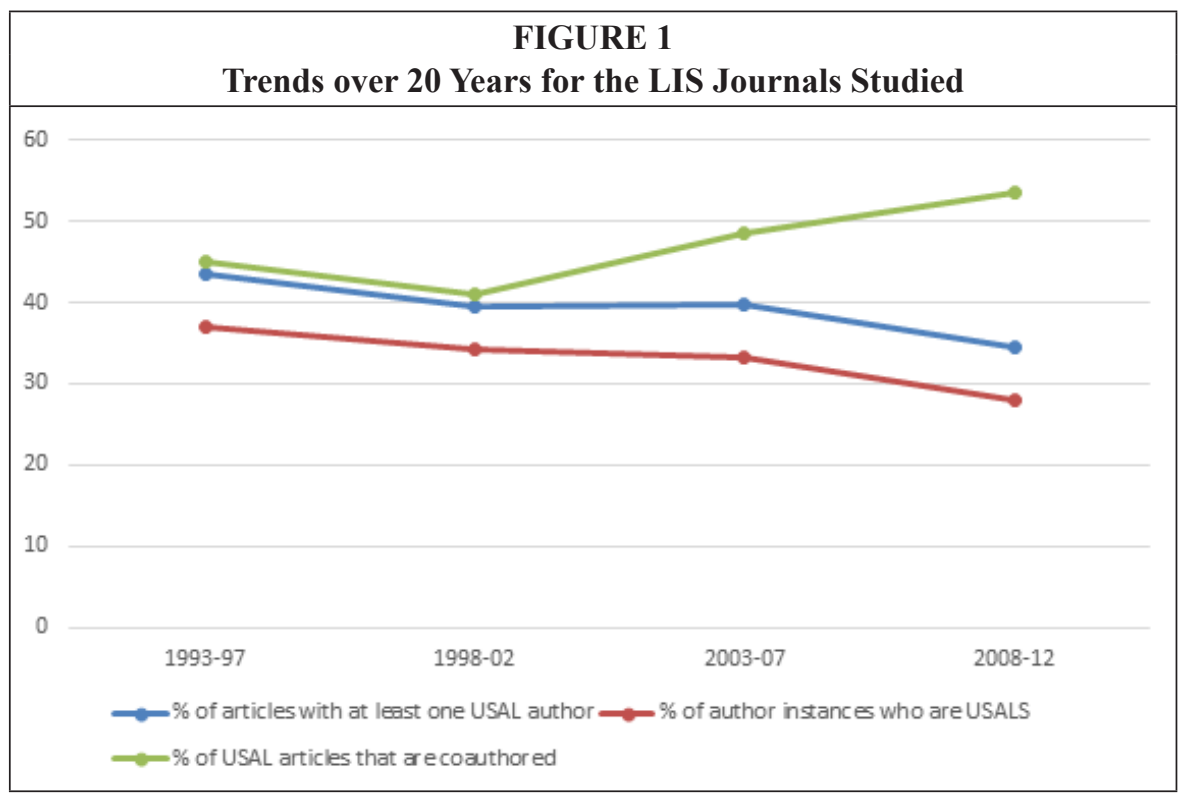

or librarians may be increasingly turning to coauthorship in response to greater expectations for publication. The data do suggest that an increase in coauthorship alone cannot raise the overall productivity of a population of authors and may decrease that productivity due to fewer sole-authored articles.

The data also suggest that the overall contributions to the journal literature are coming from a small percentage of U.S. academic librarians and libraries. This study allowed a comparison between 2003-2007 and 2008-2012 of the number of unique USAL names and the number of unique institutions. There were 2,182 unique USAL author names in 2003-2007 and 2,268 in 2008-2012. While these two counts add up to 4,450, the number of unique USAL author names for the ten years is 3,870, indicating that 580 USAL authors (15\%) published in both time periods. Most USAL authors published only once in ten years, 1,602 in 2003-2007 and 1,688 in 2008-2012. The National Center for Education Statistics reported that, in fall 2012, there were 26,606 librarians at 3,172 responding U.S. academic libraries (out of 3,793 U.S. academic libraries surveyed). ${ }^{26}$ These data indicate that less than 10 percent of USALs published a peer-reviewed journal article in one of the major LIS journals studied during a five-year period.

The study team found that 515 unique academic institutions for 2003-2007 and 511 for 2008-2012 contributed one or more peer-reviewed articles to the journals studied. If all were unique institutions, the ten-year total would be 1,026 academic institutions, but the count for the ten-year period totaled 696. This means that 330 academic institutions (47\%) were represented in both five-year data sets; 53 percent of academic institutions were home to one or more USAL authors in only one of the five-year periods. The National Center for Education Statistics surveyed 3,793 U.S. academic libraries, so these data indicate that about 13.5 percent of U.S. academic libraries contributed a peer-reviewed journal article to one of the major LIS journals studied in either five-year periods. In terms of the ten-year period studied, 18.4 percent of U.S. academic libraries contributed a peer-reviewed article.

For each of the journals studied, table 2 shows the percentages of articles with one or more USAL authors and the percentages of authors who are USALs. The Canadian Journal of Information and Library Science likely attracts mainly Canadian authors, hence 


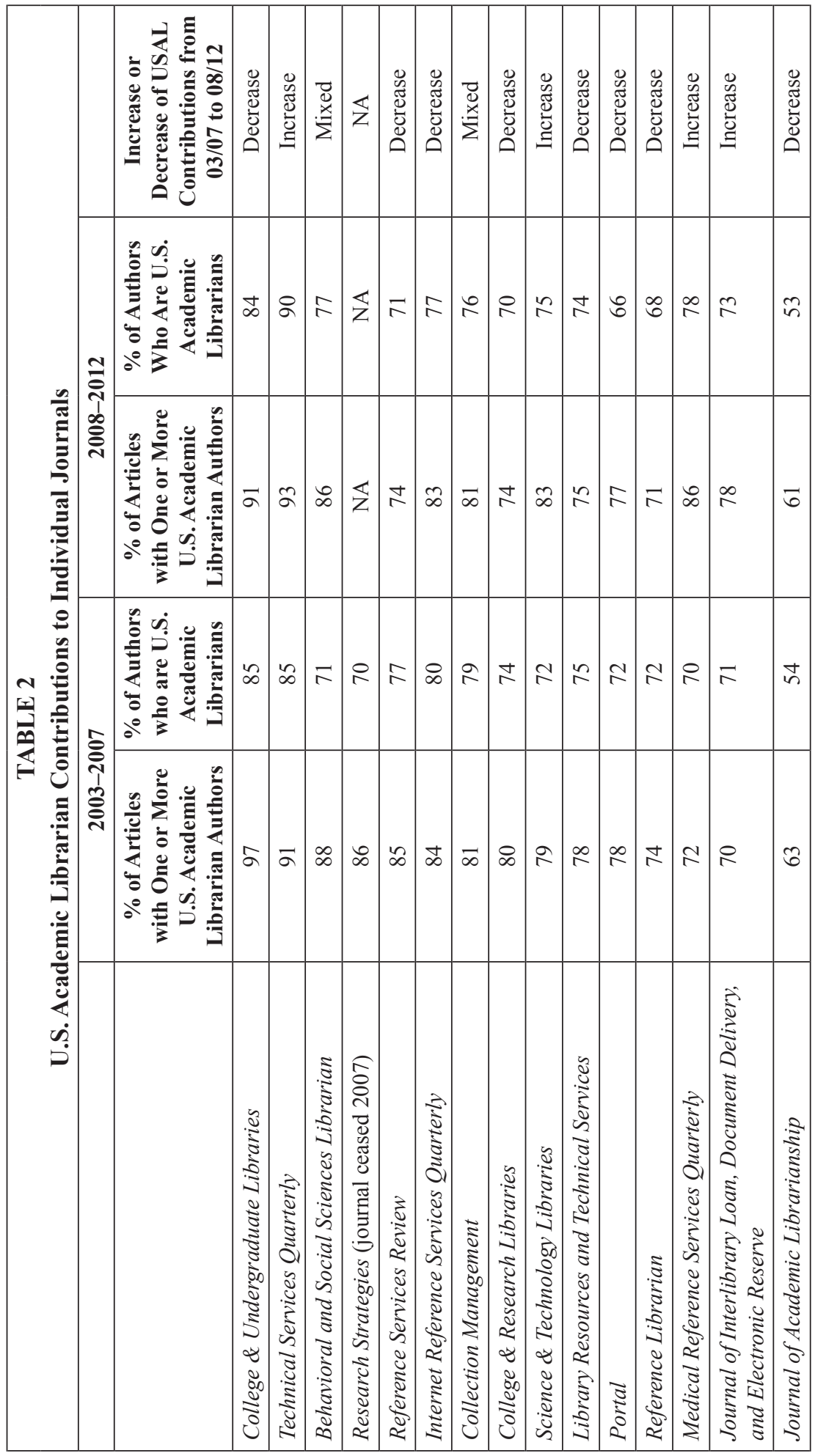




\begin{tabular}{|c|c|c|c|c|c|c|c|c|c|c|c|c|c|c|c|c|c|}
\hline & & 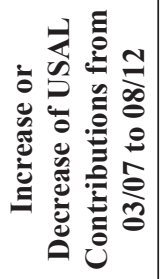 & 艺 & 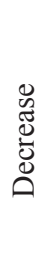 & 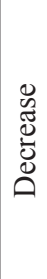 & 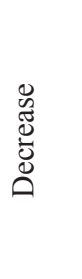 & $\begin{array}{l}\overrightarrow{0} \\
\stackrel{\ddot{x}}{\Sigma}\end{array}$ & 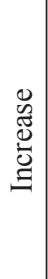 & 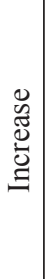 & 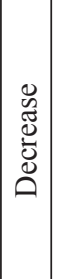 & 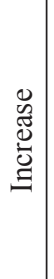 & 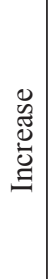 & 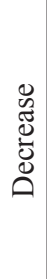 & 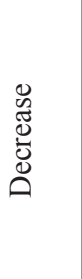 & 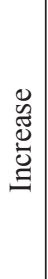 & 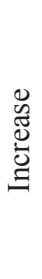 & 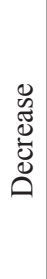 \\
\hline & $\stackrel{2}{3}$ & 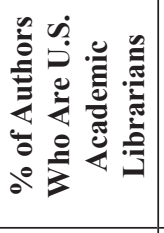 & Z & ले & 守 & $\bar{n}$ & in & $\stackrel{\infty}{n}$ & 8 & $\bar{n}$ & ষ & $n$ & $\bar{m}$ & $\hat{m}$ & $\bar{m}$ & ले & $\stackrel{0}{0}$ \\
\hline 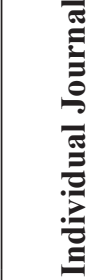 & 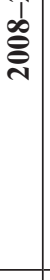 & 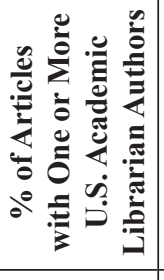 & $\overleftrightarrow{Z}$ & $\infty$ & 借 & $n$ & J & $\stackrel{\infty}{n}$ & 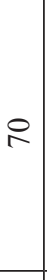 & ๖ & $\widehat{6}$ & 3 & $\hat{m}$ & $n$ & $\mathscr{f}$ & 尹 & $\cong$ \\
\hline 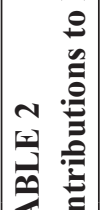 & $\hat{\varnothing}$ & 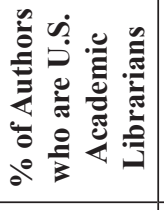 & $\exists$ & $i n$ & in & in & in & $\bar{n}$ & q & g) & అ & $n$ & fo & $\stackrel{n}{+}$ & নे & $\Xi$ & 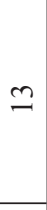 \\
\hline 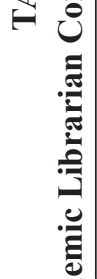 & 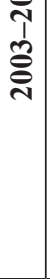 & 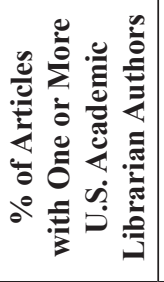 & $\widehat{6}$ & $\vec{\sigma}$ & $\overline{6}$ & $\vec{\sigma}$ & 8 & in & in & in & 으 & o & lo & $\mathscr{\sigma}$ & ల) & $\stackrel{\bullet}{-}$ & $\cong$ \\
\hline $\begin{array}{c}\tilde{u} \\
\dot{u} \\
\dot{\rho} \\
\dot{\rho}\end{array}$ & & & 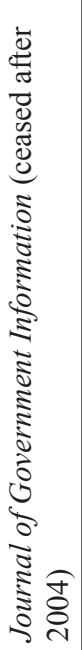 & $\frac{\tilde{s}}{0}$ & 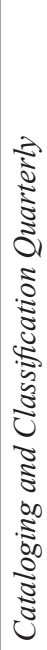 & 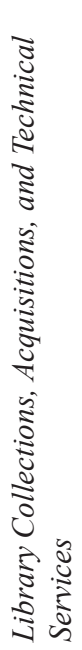 & 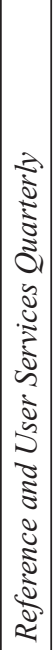 & 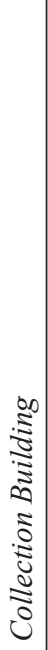 & 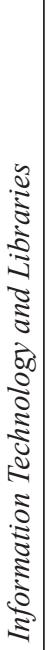 & 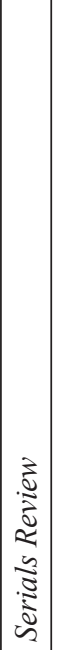 & 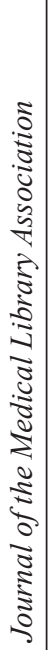 & 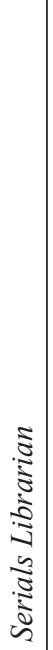 & 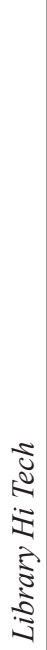 & 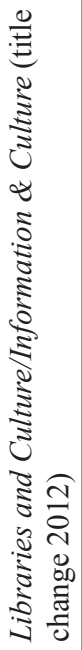 & 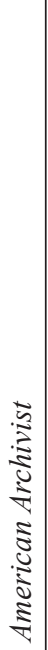 & 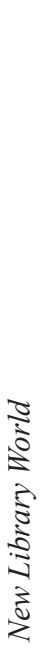 & 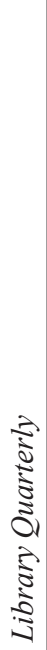 \\
\hline
\end{tabular}




\begin{tabular}{|c|c|c|c|c|c|c|c|c|c|c|c|c|c|c|c|}
\hline & & 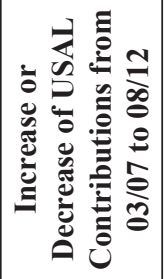 & 总 & 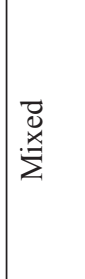 & 总 & 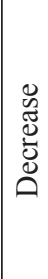 & 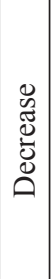 & $\stackrel{\vec{\Delta}}{\stackrel{\vec{x}}{\Sigma}}$ & 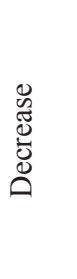 & 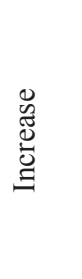 & $\begin{array}{c}0 \\
\text { E్ } \\
\tilde{\mathscr{N}}\end{array}$ & 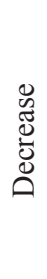 & 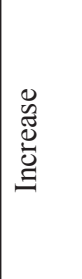 & 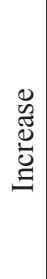 & 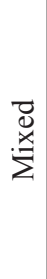 \\
\hline & $\stackrel{N}{\theta}$ & 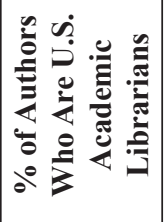 & $a$ & in & $\nabla$ & - & $\sim$ & $\nabla$ & - & $\sim$ & 0 & 0 & in & $\begin{array}{l}\infty \\
\stackrel{\sim}{\sigma}\end{array}$ & $\bar{n}$ \\
\hline & 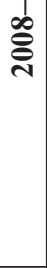 & 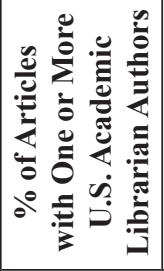 & 으 & 으 & $\infty$ & - & $m$ & 0 & - & $m$ & - & 0 & $\hat{6}$ & $\begin{array}{l}\infty \\
\infty \\
\dot{\sigma}\end{array}$ & $\infty$ \\
\hline 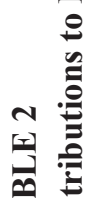 & 5 & 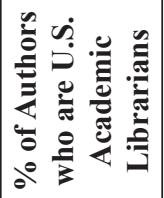 & $\infty$ & $\stackrel{\varrho}{\circ}$ & in & $n$ & 0 & $m$ & $\sim$ & - & 0 & - & 0 & $\stackrel{\vec{r}}{\dot{\gamma}}$ & $\vec{n}$ \\
\hline 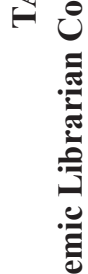 & సิ & 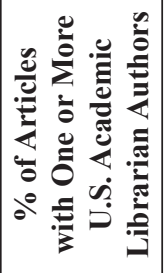 & 으 & $a$ & $\infty$ & $r$ & 0 & 0 & $m$ & $\sim$ & - & - & 0 & 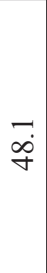 & in \\
\hline 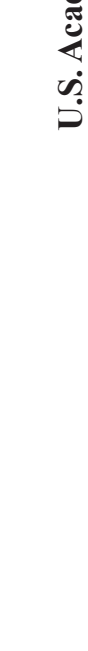 & & & 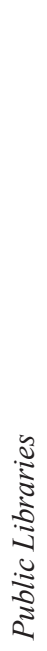 & 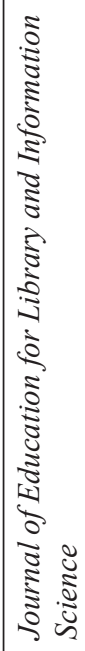 & 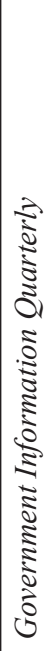 & 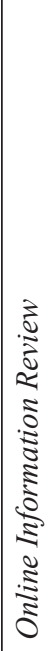 & 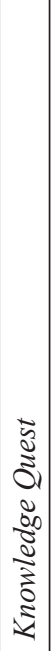 & 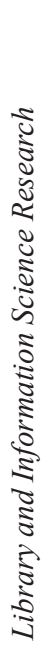 & 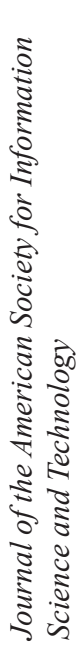 & 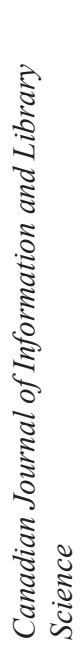 & 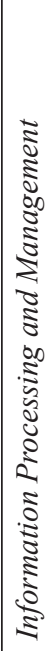 & 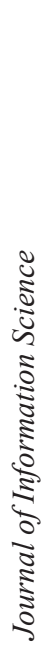 & 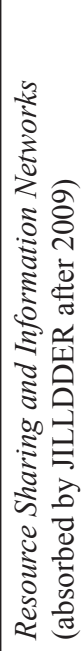 & 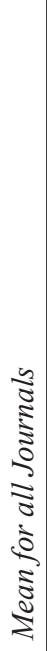 & 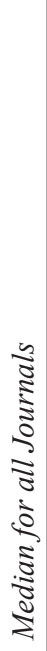 \\
\hline
\end{tabular}


the low number of USAL authors. The range of USAL authorship by journal was very large, from 0 percent to 97 percent. Of the journals for which data was available for both time periods, nineteen journals showed a decrease in U.S. academic librarian involvement, while twelve showed an increase. Seven were mixed in nature when comparing the percentage of articles by USAL authors with percentage of authors who were USALs - one measure increased while the other decreased, or one stayed the same while the other measure changed. One journal stayed the same for both measures. The mean percentage of articles with at least one USAL author for all journals increased slightly from 2003-2007 to 2008-2012 (from 48.1\% to 48.8\%), while the median increased from 57 percent to 58 percent. The mean percentages of authors who were U.S. academic librarians for all journals increased from 43.7 percent to 43.8 percent, while the median percentage stayed the same from both time periods (51\%). The journal Resource Sharing and Information Networks had the highest increases of any journal studied, but this was due to an unusual set of circumstances in which the journal published only three issues between 2003 and 2007, then restarted in 2008, before incorporating into the Journal of Interlibrary Loan, Document Delivery and Electronic Reserve. ${ }^{27}$ Overall, there was much variability in the patterns of authorship in the journals studied. While most journals saw decreases in USAL contributions, those that did see increases were of a high enough percentage change to keep the means and medians of percentages for all journals about the same for the two time periods studied. The authors expected both to decrease, but they did not.

The present study identified 3,913 refereed articles that had at least one USAL author, and those articles included 6,308 instances of USAL authorship. Table 3 shows the productivity patterns of academic librarians for ten years and also for each fiveyear period. Results were similar to earlier findings by WHW but showed a slight increase in the percentage of publishing academic librarians who published three or more articles within five years. Regarding productivity benchmarks for an individual, WHW found that 6.08 percent of USAL authors studied in the 1993-1997 period and 7.40 percent in the 1998-2002 period published three or more articles. The present study found a slight increase to 9.60 percent for 2003-2007, followed by a decrease to 8.14 percent for 2008-2012. So a USAL author who published three or more articles was in the top 6 to 7 percent from 1993-2002, but from 2003-2012 was in the top 8 to 9 percent of USALs who published in peer-reviewed journals within a five-year period. This is consistent with an increase in coauthorship rates combined with a decrease in the number of articles. Overall, the number of authors $(2,182$ to 2,268$)$ and the number of author instances $(3,120$ to 3,188) increased from 2003-2007 to 2008-2012, while the number of articles with a USAL author decreased from 1,997 to 1,916. The combination of more author instances with fewer articles resulted in the feat of publishing three or more articles in five years being slightly less rare. While overall productivity of the USAL librarians in terms of number of articles declined, increased coauthorship slightly raised the percentage of high-producing USAL authors.

To better understand the characteristics of the most productive institutions, the status of the librarians and staffing size of the libraries were examined. Table 4 documents institutional productivity, staffing size, and librarian status for the top-producing libraries over the ten-year period of this study and each of the four five-year periods of this study and WHW's previous studies. Of the top twenty high-publication libraries listed, seventeen were ARL libraries and eighteen had the Carnegie designation of Doctoral University Highest Research Activity for 2015, with the other two (UNLV and Southern Illinois) classed as Doctoral University Higher Research Activity.

The University of Illinois at Urbana-Champaign ranked first in the number of articles produced for the ten-year period 2003-2012, and also for two five-year pe- 


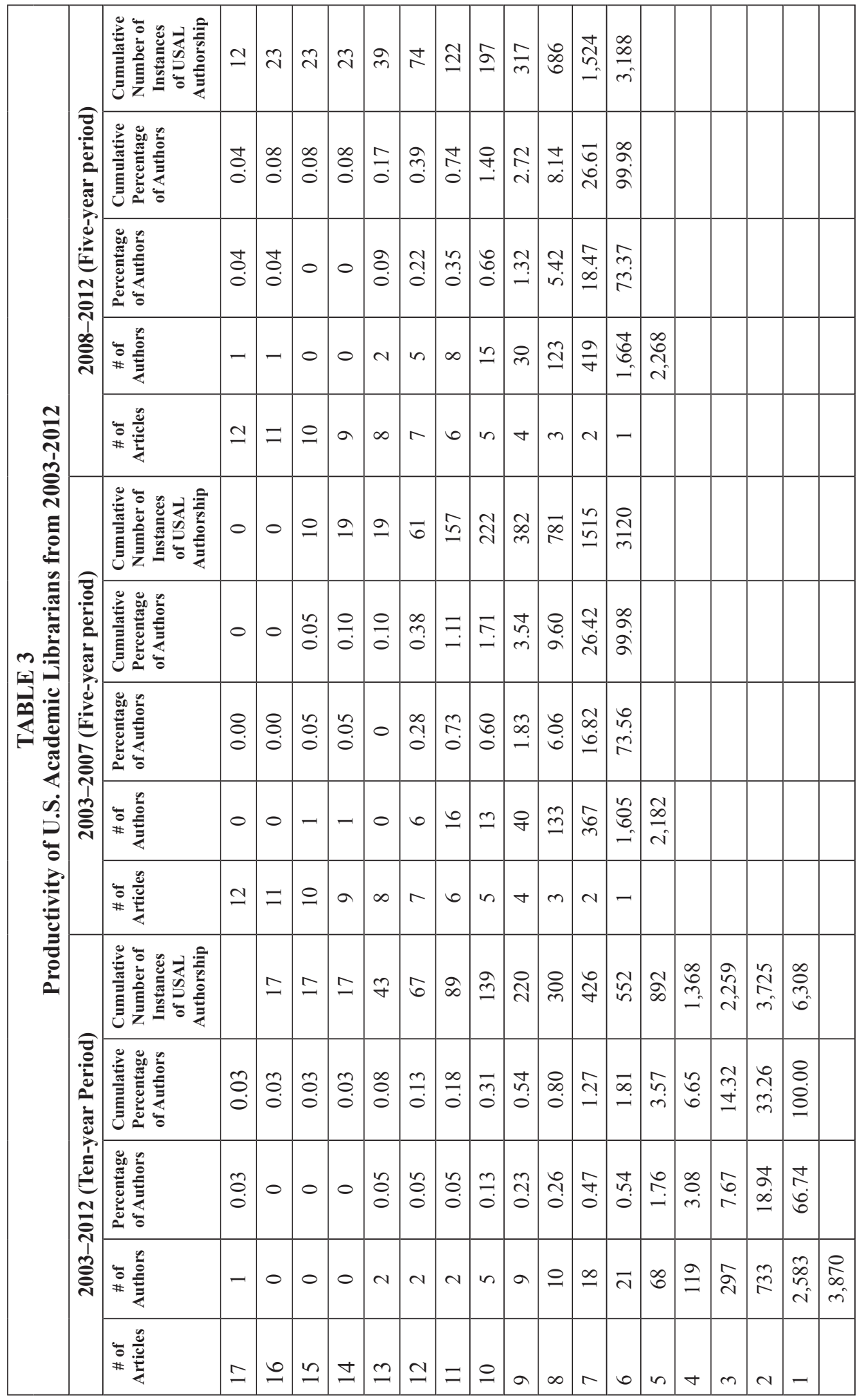




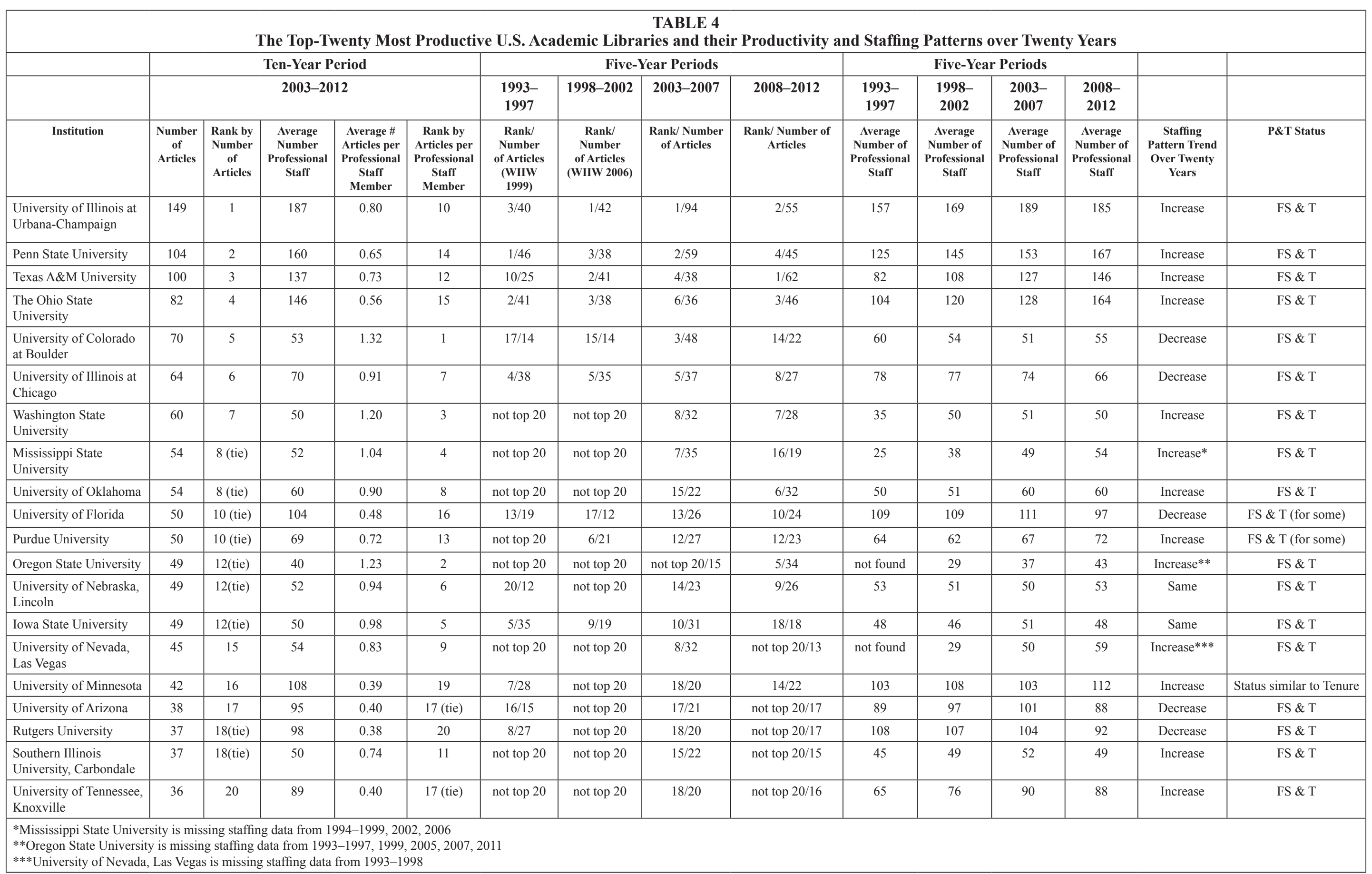


riods, 1998-2002 and 2003-2007. Texas A\&M rose from a rank of tenth in 1993-1997 to first in the five-year period 2008-2012. Eight universities ranked in the top twenty for number of articles in the ten-year period and also in each five-year period. Washington State University, Mississippi State, and University of Oklahoma appeared in the top twenty just in the last two five-year periods, and Oregon State only in the last five-year period. This is consistent with the trend at Oregon State reported by Wirth, Kelly, and Webster. ${ }^{28}$ All of the academic libraries in the top twenty were at public universities. This is a change from the previous time periods studied by WHW, which found private institutions such as Harvard, Yale, Cornell, and Vanderbilt in the top twenty.

For each academic library that made it into the top twenty in terms of the number of articles published from 2003 to 2012, the authors investigated staffing patterns as reported by ARL or ACRL statistics. For the ten-year period 2003-2012, the average number of professional staff was calculated, and the rank by number of articles per professional staff member was also determined. As shown in table 4, the average number of professional staff varied substantially, from a high of 187 for the University of Illinois at Urbana-Champaign Library to a low of forty for Oregon State University Library. The University of Colorado at Boulder ranked first in number of articles per professional staff while ranking fifth in the number of articles published. While this ranking is interesting and perhaps the most equitable, due to the time involved, it was only calculated for the top twenty libraries in terms of number of articles produced and not for each of the 696 libraries represented in this study.

The five-year averages of professional staff were examined for the top twenty article-producing libraries. Only thirteen libraries showed an increase over twenty years in average number of professional staff. Five showed a decrease and two stayed the same. Texas A\&M Library had an increase of 55 percent, which may be a factor in the increased number of articles that earned it the top ranking by 2008-2012. On the other end of the spectrum, the University of Illinois at Chicago's professional staffing declined by 15 percent, and their ranking for the number of articles published declined from fourth in 1993-1997 to eighth by 2008-2012. Of those in the top twenty, there was a strong Pearson correlation between the number of articles and the number of professional staff $\mathrm{r}(18)=.747(P<.0002)$. This correlation was stronger than the one found by Seaman but was also run on a smaller sample size. ${ }^{29}$

The study team examined the status of librarians at each of the twenty libraries. At all but one, some or all of the librarians had faculty status with tenure (FS\&T). The exception offered a status similar to tenure. Two were listed as having a mix of statuses, with faculty status and tenure available for some positions. This is another indication that faculty status and tenure are associated with high publishing activity among U.S. academic librarians, encouraging the voices of practitioners to be heard in the professional literature.

\section{Conclusion}

When librarians undergo campus-level review for promotion and/or tenure, it can be helpful to speak to national norms for publication. The present study provides benchmarks that can apply to evaluation of academic librarians who are assessed for their publication productivity. The study also documents both the substantial contribution of U.S. academic librarians to their field's literature and a long-term trend of decline in the proportion of that contribution. The results suggest that an increase in coauthorship rates resulted in more articles for individuals (author instances), but not more articles for the profession. Large, public, research-intensive universities had high-contributing libraries, but some experienced staffing decreases that impacted productivity. 
The decline in academic librarians' overall publication rates raises questions that deserve further investigation. Does an aging library workforce with more tenured librarians result in fewer untenured librarians with the most incentive to produce articles? Just as some private research universities eliminated their library schools, is the culture of those universities now less encouraging of academic librarian scholarship? Or are expectations for publication increasing for librarians at public universities to such a degree that private universities' libraries have just moved down on the list of top contributors despite no changes in publication rates? As academic libraries attempt to expand the scope of their services, are they spreading their librarians too thin, especially in cases of reduced professional staffing? Is the construction of work assignments that call on practitioners to cover a wide range of responsibilities so fragmenting librarians' attention that they are not developing research foci? Are the complexities of rapid change coupled with widespread budgetary pressures resulting in less time for research? Are academic librarians sharing their scholarship in other ways, such as book chapters or blogs, or in different types of journals? Is the increasing rate of coauthorship resulting in fewer articles, but do those articles report on bigger projects that need more contributors?

Evidence of decline in the volume of publication by academic librarians should be a cause for concern. U.S. academic librarians bring a unique perspective and a focus on library practice, often evidence-based, to the LIS literature. The profession needs to take notice of evidence of a decrease in contributions by practitioners to the literature, investigate the factors that may be contributing to the situation, and see if any action can be taken to further support publishing by USAL authors. The current library environment is one of rapid, technology-driven change. To respond well to that change, librarians must have a strong body of research that analyzes their situation and the services of their libraries to inform and improve practice.

\section{Notes}

1. William H. Walters and Esther Isabelle Wilder, “Disciplinary, National, and Departmental Contributions to the Literature of Library and Information Science, 2007-2012," Journal of the Association for Information Science and Technology, first published online 29 April 2015, doi:10.1002/ asi.23448; S. Craig Finlay, Caoqun Ni, Andrew Tsou, and Cassidy Sugimoto, "Publish or Practice? An Examination of Librarians' Contributions to Research," portal: Libraries and the Academy 13, no. 4 (Oct. 2013): 403-21, doi:10.1353/pla.2013.0038.

2. Ann C. Weller, Julie M. Hurd, and Stephen E. Wiberley Jr., "Publication Patterns of U.S. Academic Librarians from 1993-1997," College \& Research Libraries 60, no. 4 (July 1999): 352-62, doi:10.5860/crl.60.4.352; Stephen E. Wiberley Jr., Julie M. Hurd, and Ann C. Weller, "Publication Patterns of U.S. Academic Librarians from 1998 to 2002," College \& Research Libraries 67, no. 3 (May 2006): 205-16, doi:10.5860/crl.67.3.205.

3. Jennifer Lyn Soutter, "Academic Librarian Competency: A Description of Trends in the Peer Reviewed Journal Literature of 2001-2005," Partnership: The Canadian Journal of Library and Information Practice and Research 2, no. 1 (2007), available online at https://journal.lib.uoguelph. ca/index.php/perj/article/view/252\#.Vb_TbbX9y5i [accessed 3 August 2015].

4. Barbara Norelli and Timothy L. Harper, "Collaborative Scholarship in Academic Library Literature: Who, What, and When," College \& Undergraduate Libraries 20, no. 2 (2013): 173-96.

5. Colleen Kenefick and Susan E. Werner, "Bibliometric Study of Medical Reference Services Quarterly, 1982-2009," Medical Reference Services Quarterly 30, no. 1 (Jan./Mar. 2011): 1-11, doi:10 $.1080 / 02763869.2011 .540204$.

6. Susan E. Wood and Betsy Park, "The Journal-Based Publishing Activity of Tennessee Academic Librarians: 2007-2011," Southeastern Librarian 61, no. 1 (Spring 2013): 3-12.

7. Kenefick and Werner, "Bibliometric Study," 2.

8. Wood and Park, "Journal-Based Publishing Activity," 11.

9. Christopher Stewart, "Whither Metrics, Cont.: Assessing Publication Output of Academic Library Practitioners across Different Types of Institutions," Journal of Academic Librarianship 36, no. 6 (Nov. 2010): 546-48. 
10. Quinn Galbraith, Elizabeth Smart, Sara D. Smith, and Megan Reed, "Who Publishes in Top-Tier Library Science Journals? An Analysis by Faculty Status and Tenure," College E Research Libraries 75, no. 5 (Sept. 2014): 724-35, doi:10.5860/crl.75.5.724.

11. Scott Seaman, "North American Institutions Most Frequently Represented In High-impact Library Journals," LIBRES: Library and Information Science Research Electronic Journal 18, no. 2 (September 2008), available online at http://libres-ejournal.info/wp-content/uploads/2014/06/ Vol18_I2_Seaman_FINAL.pdf [accessed 4 August 2015].

12. Finlay, Ni, Tsou, and Sugimoto, "Publish or Practice?" 411.

13. Andrea A. Wirth, Maureen Kelly, and Janet Webster, "Assessing Library Scholarship: Experience at a Land Grant University," College E Research Libraries 71, no. 6 (Nov. 2010): 510-24, doi:10.5860/crl-51r1.

14. Rickey D. Best and Jason Kneip, "Library School Programs and the Successful Training of Academic Librarians to Meet Promotion and Tenure Requirements in the Academy," College E Research Libraries, 71, no. 2 (Mar. 2010): 97-114, doi:10.5860/0710097.

15. Walters and Wilder, "Disciplinary, National, and Departmental Contributions," 7.

16. Best and Kneip, "Library School Programs," 106

17. Catherine Sassen and Diane Wahl, "Fostering Research and Publication in Academic Libraries," College E Research Libraries 75, no. 4 (July 2014): 458-91, doi:10.5860/crl.75.4.458; John Cosgriff, Donald Kenney, and Gail McMillan, "Support for Publishing at Academic Libraries: How Much Exists?" Journal of Academic Librarianship 16, no. 2 (1990): 94-97.

18. Weller, Hurd, and Wiberley, "Publication Patterns 1993 to 1997," 355; Wiberley, Hurd, and Weller, "Publication Patterns 1998 to 2002," 207.

19. "The Carnegie Classification of Institutions for Higher Education" available online at http:// carnegieclassifications.iu.edu/ [accessed 18 September 2014].

20. "Penn State Campuses" available online at www.psu.edu/academics/campuses [accessed 25 September 2015].

21. "Academic Librarian Status" available online at http://academic-librarian-status.wikispaces. com/home\#faculty_tenure [accessed 2 June 2015].

22. Martha Kyrillidou, Shankeka Morris, and Gary Roebuck, ARL Statistics 2011-2012 (Washington, D.C.: Association of Research Libraries, 2013) and previous years back to 1992-1993.

23. Association of College and Research Libraries, 2012 Academic Library Trends and Statistics (Chicago, Ill.: Association of College and Research Libraries, 2013), and previous years back to 1998; Association of College and Research Libraries, ACRL University Library Statistics 1996-97 (Chicago, Ill.: Association of College and Research Libraries, 1998), and previous years back to 1992-93.

24. Finlay, Ni, Tsou, and Sugimoto, "Publish or Practice?" 411.

25. Kenefick and Werner, "Bibliometric Study," 4.

26. T. Phan, L. Hardesty, and J. Hug, Academic Libraries: 2012 (NCES 2014-038) (Washington, D.C.: U.S. Department of Education National Center for Education Statistics, 2014), available online at http://nces.ed.gov/pubs2014/2014038.pdf [accessed 10 August 2015].

27. Barbara J. Stites and Rebecca Donlan, "From the Editors," Resource Sharing E Information Networks 19, no. 1/2 (2008): 1-2, doi:10.1080/07377790802587655

28. Wirth, Kelly and Webster, "Assessing Library Scholarship," 516.

29. Seaman, "North American Institutions in High-Impact Journals," 16. 